\title{
The Use of Intraoperative Ultrasonography in Intradural Spinal Tumor Surgery
}

\author{
Ersin HACIYAKUPOGLU ${ }^{1}$, Evren YUVRUK², Mehmet Resid ONEN², Sait NADERI ${ }^{2}$ \\ ${ }^{1}$ Heinrich-Braun-Klinikum, Department of Neurosurgery, Zwickau, Germany \\ ${ }^{2}$ Health and Science University, Umraniye Education Research Hospital, Department of Neurosurgery, Istanbul, Turkey \\ This study has been presented at the $29^{\text {th }}$ Annual Scientific Congress of the Turkish Neurosurgical Society, between 17 April - 21 April 2015 at Antalya, \\ Turkey
}

Corresponding author: Evren YUVRUK evreny82@gmail.com

\section{ABSTRACT}

AIM: To review our experience gained from the use of intraoperative ultrasonography (IOUSG) in intradural spinal tumor surgery. MATERIAL and METHODS: IOUSG was used during surgery of 69 intradural spinal tumors, operated on between 2012 and 2016. A 5-8 MHz probe of IOUSG was used, before and after durotomy to perform the exact durotomy and myelotomy, and after tumor resection, to detect a residual tumor. A retrospective review of parameters including demographic data, localization and histopathology of the tumour, IOUSG findings, and the amount of tumor resection was made.

RESULTS: In a total of 69 intradural spinal tumors (42 extramedullary, and 27 intramedullary tumors) IOUSG was used during surgery. Total excision was performed in 68 cases, and subtotal excision in one case. Pre-durotomy IOUSG showed sufficient laminectomy in 62 cases. In 7 cases, as the IOUSG failed to show all borders of the tumor, laminectomy was extended.

CONCLUSION: IOUSG is an important tool, which contributes to intradural spine surgery. This modality shows the tumor appearance before durotomy, and is therefore helpful in deciding the amount of laminectomy and duratomy in addition to the exact location of myelotomy. It also provides the surgeon with information about residual tumor after excision, thereby increasing the safety and success of the surgical procedure.

KEYWORDS: Intradural spine tumor, Intraoperative ultrasonography, Spine surgery

\section{INTRODUCTION}

$\mathrm{P}$ rimary spinal tumors account for $4-8 \%$ of all central nervous system tumors. Although most of these tumors are benign $(2,3,13)$, surgery remains risky and technically challanging. In order to reduce the surgery-related risks, and to increase the safety and success of the procedure, many imaging and neurophysiological modalities have been introduced.

Intraoperative ultrasonography (IOUSG) is an important imaging modality that has been used for many years in cerebral tumor surgery. Its successful use in brain surgery led many neurosurgeons to use it in intradural spinal tumor surgery (47). The main contribution to surgery includes detection of the exact tumor localisation and the resection amount (6-9). A recent study by Harel and Knoller showed that IOUSG changed the course of surgery in $63 \%$ of the cases (6).

Toktas et al. reported that the sensitivity of IOUSG for the determination of the extent of resection was up to $92 \%$ and that IOUSG is effective in the identification of tumor boundaries and the protection of spinal cord vessels (15). The aim of this study was to review our experience gained from the use of IOUSG, and state the benefits of IOUSG.
Ersin HACIYAKUPOGLU (D) : 0000-0003-3836-4718 Evren YUVRUK (1): 0000-0002-2945-7433
Mehmet Resid ONEN (1) : 0000-0003-4353-9068

Sait NADERI (10): 0000-0002-6784-4270 


\section{- MATERIAL and METHODS}

IOUSG was used during the surgery of 69 patients with an intradural spinal tumor between 2012 and 2015. A retrospective review was made of parameters including demographic data, localization and histopathology of the tumour, IOUSG findings, and the amount of tumor resection.

IOUSG was performed using a BK medical, B P 10 Ultraviev ultrasonograpy device with a probe of $5-8 \mathrm{MHz}$ (Figure 1). All operations were performed with the patient in the prone position and using a posterior approach. After fluoroscopic determination of the exact level of the tumor, a midline skin incision was made and total or hemi laminectomy was performed. IOUSG was used to show the tumor in both axial and sagittal views.

IOUSG was performed in three major steps;

1. After laminectomy and before durotomy: IOUSG was performed in this step to identify the localization of the tumor with respect to resected laminae. In cases with incomplete visualization of the intradural tumor, laminectomy should be extended.

2. After durotomy- before myelotomy: IOUSG in this step was performed to decide the best and least myelotomy with respect to tumor location.

3. After tumor resection: IOUSG in this step was performed to detect rest tumor, if any.

A postoperative MRI scan with and without Gadolinium was also performed within the first 48 hours to all the patients to determine a rest tumor.

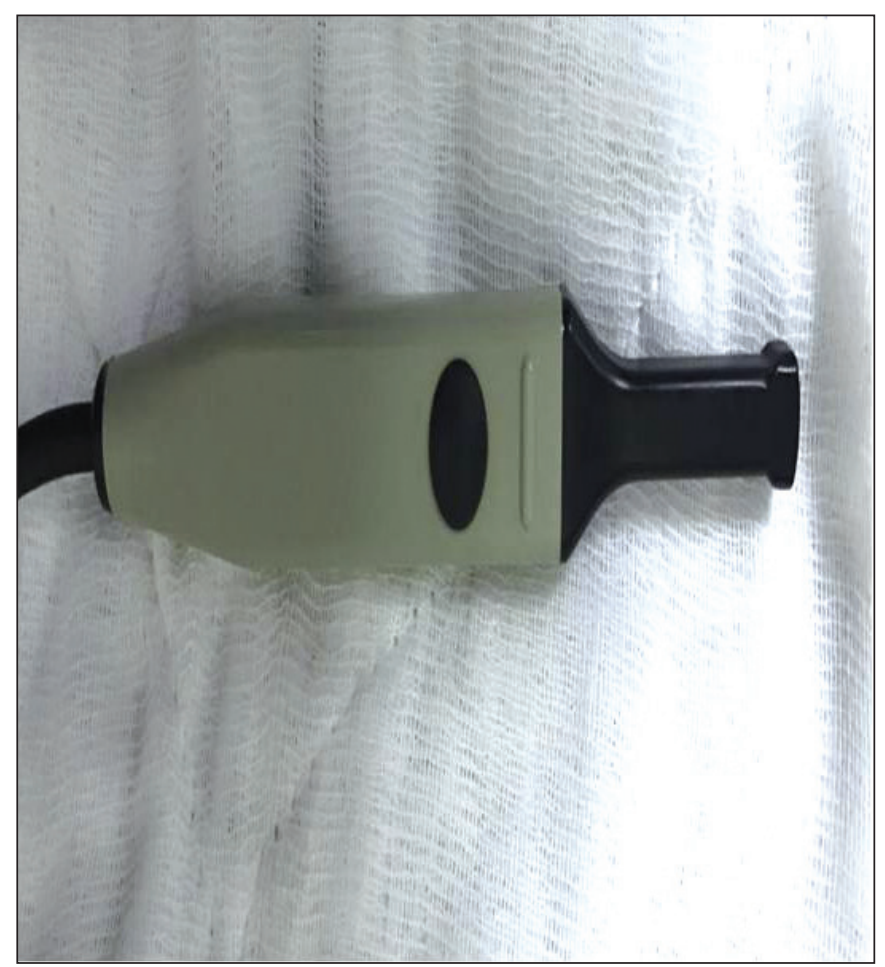

Figure 1: The IOUSG device probe.

\section{RESULTS}

The patients comprised 28 males and 41 females. The diagnoses were made from non-contrast and contrast enhanced MRI scans. The tumors were found to be localized in the cervical spine in 19 cases, in the thoracic spine in 33, and in the lumbar spine in 17 cases. A total of 42 tumours were intradural- extramedullary, and 27 were intradural- intramedullary. Histopathological examination of the intradural- intramedullary tumors identified 14 ependymomas $(6$ cervical, 6 thoracic, 2 conus), 7 astrocytomas (1 cervical, 6 thoracic), 3 dermoid tumors ( 2 thoracic, 1 lumbar), 2 hemangioblastoma (1 cervical, 1 thoracic), and 1 cavernoma (cervical).

Histopathological examination of the intradural-extramedullary tumors identified 21 schwannomas (4 cervical, 7 thoracic, 10 lumbar), 18 meningiomas (5 cervical, 12 thoracic, 1 lumbar), 2 cauda equina myxopapillary ependymomas, and 1 endodermal cyst (lumbar).

The laminectomy levels were correlated with the preoperatively MRI scans in 62 patients. However, in 7 patients (10.1\%), the laminectomy level needed to be extended in one direction based on the IOUSG findings.

Myelotomy was also done based on the information provided by IOUSG. After each tumour resection, IOUSG was performed to determine any rest tumor, and in cases so determined, additional resection was performed. Total resection was possible in 68 cases and in 1 case with infiltrative tumor tissue, which also showed changes in neuromonitoring, a subtotal tumor resection was performed.

\section{Illustrative Cases}

\section{Case 1}

A 55-year old male patient was admitted to our clinic with weakness of the lower extremities, which had been ongoing for the last month. Clinical neurological findings revealed paraparesia (bilateral lower extremity muscle power 3/5), hypoesthesia below the L2 level, urinary incontinence with a positive bilateral Babinski sign, and Achilles clonus. An MRI scan with contrast identified an inradural, extramedullary mass lesion at L1 level (Figure 2A, B). Following intraoperative IOUSG, the laminectomy had to be extended (Figure 2C). The tumor was resected totally and the histopathological examination was reported as meningioma (Figure 2D).

\section{Case 2}

A 35-year old male patient was admitted to our clinic with neck pain and numbness in both hands. The neurological examination was normal. MRI scan revealed an intra- medullary tumor at the level of C2 - C4 (Figure 3A, B). Intraoperatively, after the laminectomy, the tumour levels was correctly detected on IOUSG and a total resection of the tumor was performed (Figure $3 \mathrm{C}$ ). There were no postoperative neurological deficits, and the postoperative MRI scan confirmed total resection of the tumor (Figure 3D). The histopathological examination was reported as schwannoma. 

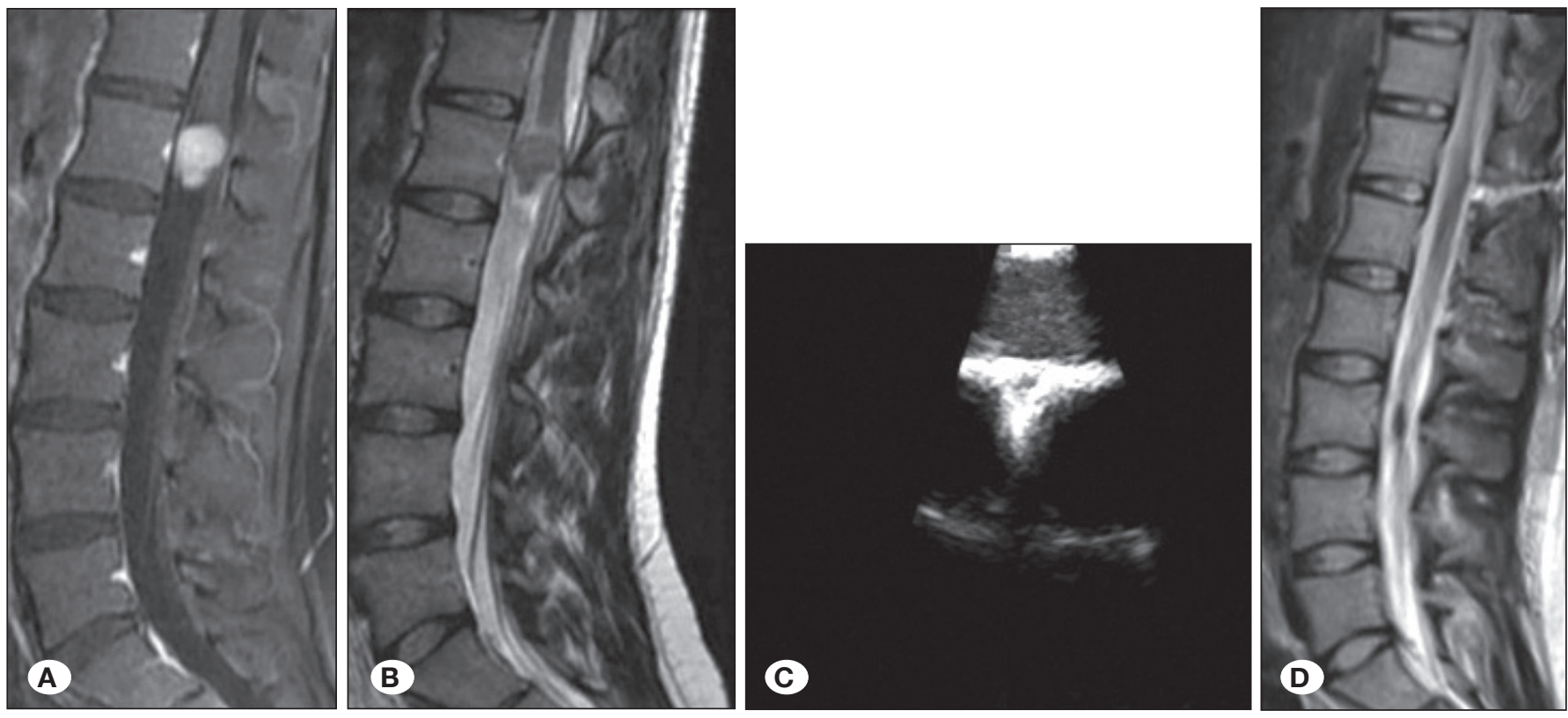

Figure 2: Sagittal T1W contrast enhanced (A) and T2W (B) MRI images of a case with L1 meningioma, C) IOUSG image of the case, D) postoperative sagittal T2W MRI image.
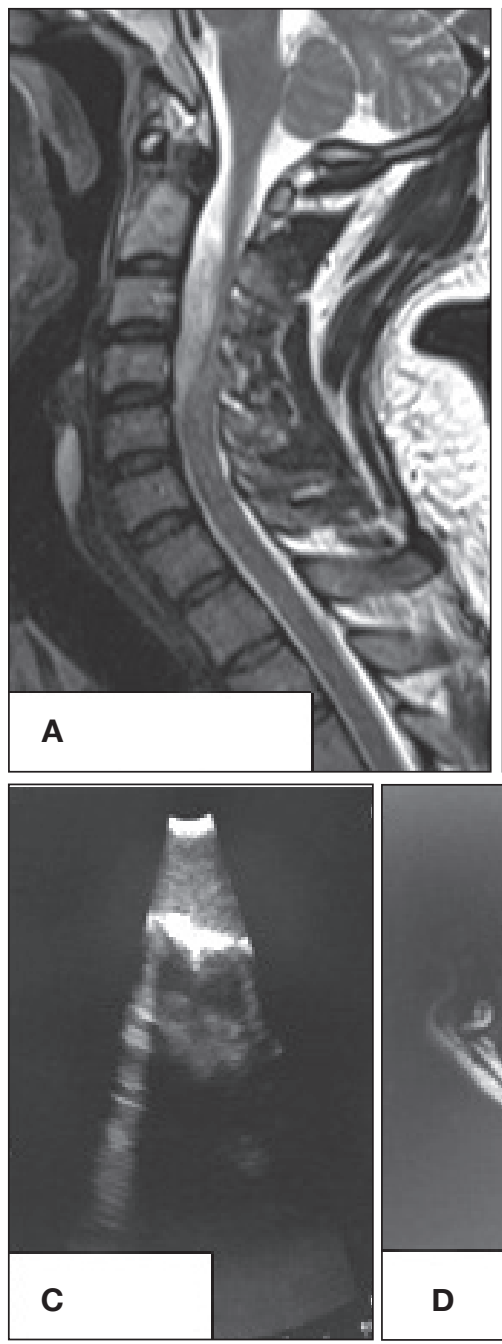
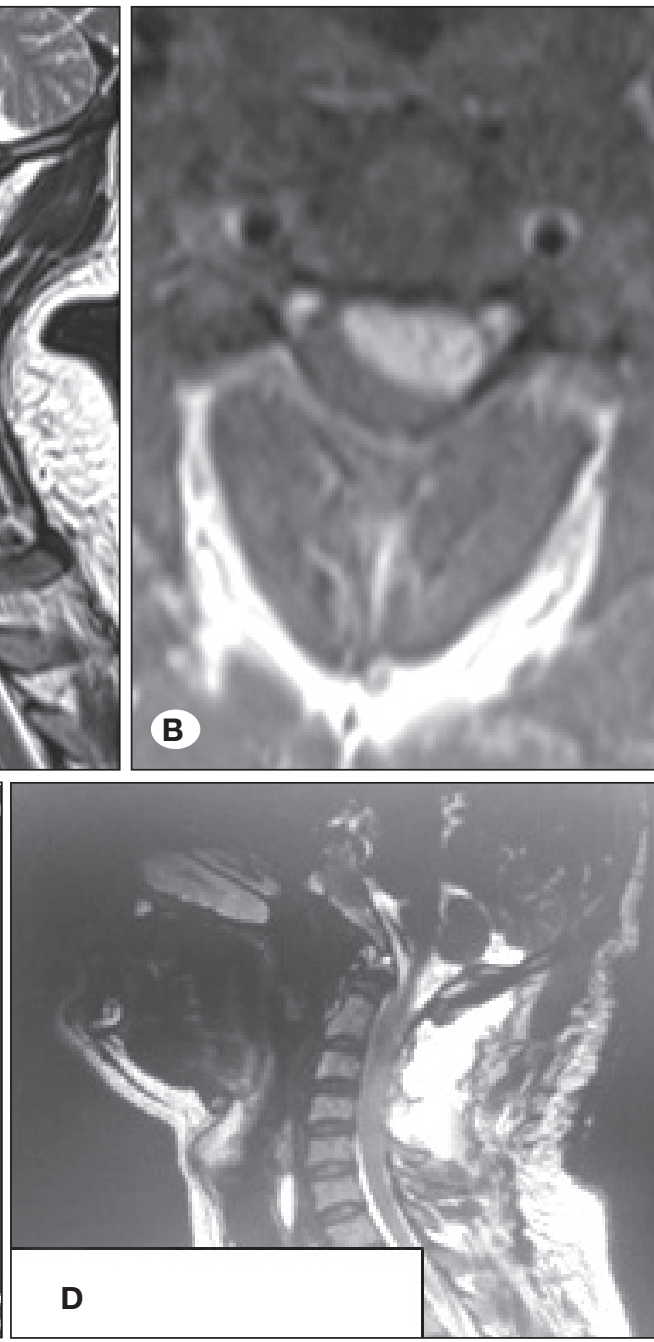

Figure 3: Sagittal (A) and axial (B) MRI images of a case with C2-4 schwannoma, C) IOUSG image of the case. D) Postoperative sagittal MRI image. 


\section{Case 3}

A 31-year old female patient was admitted to our clinic with left arm pain. There was no neurological deficit. MRI scan revealed an intradural, intramedullary tumor at level C3-4 (Figure 4A, B). Aided by IOUSG, the vascular mass was totally removed (Figure $4 \mathrm{C}$ ). The histopathologial examination revealed cavernoma. The postoperative MRI scan conifrmed the total removal of the tumor (Figure 4D).

\section{DISCUSSION}

The results of this study revaled the effectiveness and reliability of IOUSG in the detection of the amount of laminectomy, duratomy, and myelotomy. It was also found to be helpful in the detection of rest tumor.

The use of IOUSG has been described in cranial surgery for many years and there are many studies proving the effectiveness of IOUSG in cranial surgery. Therefore, the use of IOUSG in cranial surgery is recommended by many authors $(1,3-5,11,12)$. The wide use of IOUSG during cranial surgery has suggested a possible role for IOUSG in intradural spinal pathologies, such as cavernomas and tumors.

The exact localisation of spinal tumors is important. Peroperative lateral and $\mathrm{A}-\mathrm{P}$ radiographs are taken to correlate the preoperative scans with the surface anatomy. For an adequate dural opening, the spinous process of the adjacent levels usually have to be removed together with the laminae, but even so, an inadequate dural opening may still occur. With IOUSG, even after a small dural opening, the exact location of the intraspinal tumor can be detected and this allows the surgeon to limit the laminectomy and duratomy.

The aim of spinal tumor surgery should be to treat the patient without causing any additional neurological deficits, to obtain a histological diagnosis, and to provide relief of symptoms and prolongation of life. Especially in malignant tumors, extensive resection and cyto reduction is important for a better response to chemotherapy and radiotherapy. The pressure on the peritumoral tissue should be eliminated to obtain improvement of neurological functions $(5,6)$. Therefore, the surgical management of a spinal tumor, requires detailed mapping of the intradural regions around the tumor.

Most spinal intradural intramedullary tumors are low grade lesions. Detection of the transition zone between the tumor mass and surrounding structures including the syrinx and peritumoral tissue is quite important. This is critical for both safety of resection and the amount of resection. IOUSG is very helpful in the visualisation of the transitional zone, syrinx cavity and the plane between the tumor and the spinal cord.
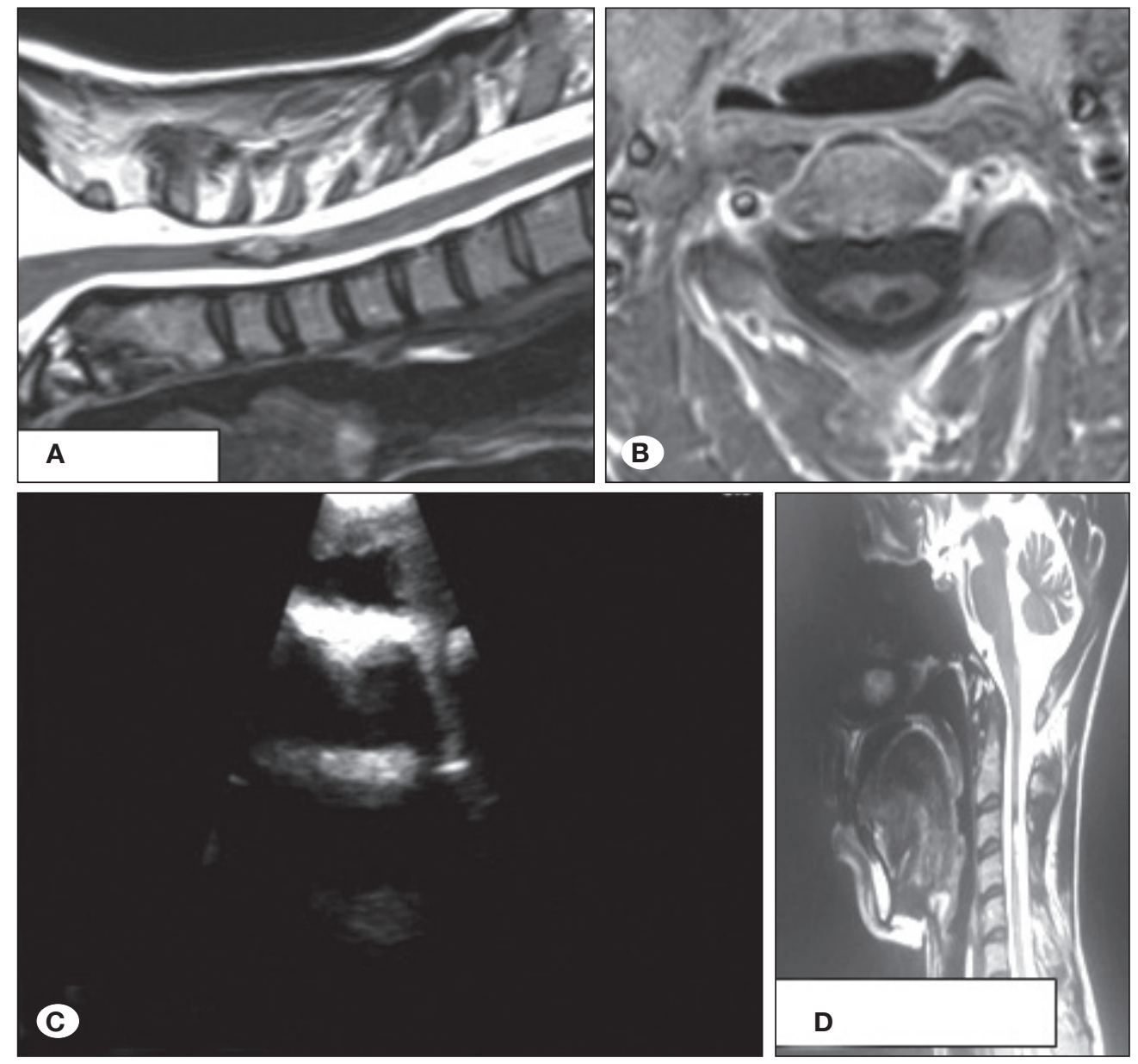

Figure 4: T2W sagittal (A) and T1W axial contrast enhanced (B) MRI images of a case with $\mathrm{C} 3$ cavernoma, C) IOUSG image of the case. D) Postoperative T2W sagittal MRI image. 
This study has also showed the effectiveness of IOUSG in the detection of borders of infiltrative intramedullary tumors.

As in intraoperative MRI, IOUSG can also be applied to detect the residual tumor after tumor resection. IOUSG has the advantage of being much cheaper than intraoperative MRI $(5,16)$.

In our clinic, IOUSG has been started to use for each spinal intradural tumor since 2012, and 69 intradural tumor operations were performed by the end of 2015. Our experience has shown that IOUSG is helpful for the localisation and resection of all spinal intradural tumors. Especially when used with neuromonitoring, safe resection without postoperative neurological deficits is highly possible.

\section{CONCLUSION}

IOUSG is very helpful in the detection of tumor localisation, and to decide the laminectomy levels. It allows safe resection of the spinal intradural tumor, and provides the surgeon with the exact localisation of the intramedullary pathology. It is a real time and non- invasive diagnostic method, which does not require an additional dura incision and helps to reduce the operation time. It also allows the surgeon to make an early postoperative diagnosis of residual tumor tissue, which is usually very helpful for a complete tumor resection.

It can be concluded that the use of IOUSG makes spinal intradural tumor surgery safer, and increases the success of the procedure.

\section{REFERENCES}

1. Bal J, Camp SJ, Nandi D: The use of ultrasound in intracranial tumor surgery. Acta Neurochirurgica 158: 1179-1185, 2016

2. Duong LM, McCarthy BJ, McLendon RE, Dolecek TA, Kruchko C, Douglas LL, Ajani UA: Descriptive epidemiology of malignant and nonmalignant primary spinal cord, spinal meminges and cauda equina tumors, United States, 2004-2007. Cancer 118: 4220-4227, 2012

3. Erdogan N, Tuncer B, Mavili E, Menku E, Kurtsoy A: Ultrasound guidance in intracranial tumor resection: Correlation with postoperative magnetic resonance findings. Acta Radiologica 46:742-749, 2005
4. Gooding GA, Boggan JE, Weinstein PR: Characterization of intracranial neoplasms by CT and intraoperative sonography. AJNR 5: 517-520, 1984

5. Hammoud MA, Ligon BL, Elsouki R, Shi WM, Schomer DF, Sawaya R: Use of intraoperative ultrasound for localizing tumors and determining the extend of resection: A comparitive study with magnetic resonance imaging. Journal of Neurosurgery 84:737-741, 1996

6. Harel R, Knoller N: Intraoperative spine ultrasound: Application and benefits. Eur Spine J 25: 865-869, 2015

7. Matsuzaki H, Tokuhashi $\mathrm{Y}$, Wakabayashi $\mathrm{K}$, Ishihara $\mathrm{K}$, Iwahashi M: Differences on intraoperative ultrasonography between meningioma and neurilemmoma. Neuroradiology 40: 40-44, 1998

8. Mimatsu K, Kawakami N, Kato F, Saito H, Sato K: Intraoperative ultrasonography of extramedullary spinal tumors. Neuroradiology 34:440-443, 1992

9. Prada F, Vetrano IG, Filippini A, Del Bene M, Perin A, Casali C, Legnani F, Saini M, DiMeco F: Intraoperative ultrasound in spinal tumor surgery. J Ultrasound 17:195-202, 1994

10. Regelsberger J, Fritzsche E, Langer N, Westphal M: Intraoperative sonography of intra- and extramedullary tumors. Ultrasound Med Biol 31: 593-598, 2005

11. Reinachter PC, van Vethoven V: Intraoperative ultrasound imaging: Practical applicability as a real- time navigation system. Acta Neurochir 85: 89-93, 2002

12. Roth J, Constantin S, Rosentelf US : Management of brain tumors in the pediatric patient. In: Kaye HA, Laws RE (eds), Brain Tumors. Edinburg: Elsevier, 2012:329-346

13. Schellinger KA, Propp JM, Villano JL, McCarthy BJ: Descriptive epidemiology of primary spinal cord tumors. J Neurooncol 87: 173-179, 2008

14. Schwartz HT, Mc Cormick CP: Spinal cord tumors in adults. In: Winn RH (ed), Youmans Neurological Surgery. Philadelphia: Elsevier, 2004:4817-4834

15. Toktas ZO, Sahin S, Koban O, Sorar M, Konya D: Is intraoperative ultrasound required in cervical spinal tumors? A prospective study. Turkish Neurosurgery 23: 600-606, 2013

16. Zhou H, Miller D, Schulte DM, Benes L, Bozinov O, Sure $\mathrm{U}$, Bertalanffy $\mathrm{H}$ : Intraoperative ultrasound assistance in treatment of intradural spinal tumors. Clin Neurol Neurosurg 113: 532-537, 2011 